\title{
Thermoenhanced osmotic power generator via lithium bromide and asymmetric sulfonated poly (ether ether ketone)/poly(ether sulfone) nanofluidic membrane
}

\author{
Yue Sun ${ }^{1,2,3}$, Yadong Wu ${ }^{1,3}$, Yuhao Hu ${ }^{1,3}$, Congcong Zhu ${ }^{1,3}$, Hao Guo ${ }^{4}$, Xiang-Yu Kong $\mathbb{D}^{1}$, Ercang Luo ${ }^{4}$, Lei Jiang ${ }^{1,3}$ and
} Liping Wen (iD)

\begin{abstract}
Osmotic energy, existing between solutions with different concentrations, is a sustainable and ecofriendly resource for solving energy issues. However, current membrane-based osmotic energy conversion technologies focus on electricity generation from an "open" system by directly mixing salt $(\mathrm{NaCl})$ solutions at room temperature. For the integrated utilization of thermal energy and higher power output performance, we demonstrate thermoenhanced osmotic energy conversion by employing highly soluble lithium bromide ( $\mathrm{LiBr}$ ) solutions, asymmetric sulfonated poly(ether ether ketone)/poly(ether sulfone) (SPEEK/PES) membranes, and $\mathrm{LiMn}_{2} \mathrm{O}_{4} /$ carbon nanotube (LMO/CNT) electrodes. The thin top layer of this heat-resistant membrane contains hydrophilic groups (i.e., the sulfonated groups in SPEEK) that are beneficial for ion-selective transport. The thermal effect on each solution is investigated, and osmotic energy conversion can be improved by regulating the heat gradient. The power density is $\sim 16.50 \mathrm{~W} / \mathrm{m}^{2}$ by coupling with a temperature gradient $\left(30^{\circ} \mathrm{C}\right)$. This work is a step forward for promoting the performance of osmotic energy conversion with thermal energy assistance and provides the basis for a closed-loop system with regenerated osmotic energy from other energy forms. Moreover, the external field-osmotic hybrid energy conversion system shows powerful potential in the energy harvesting field.
\end{abstract}

\section{Introduction}

Salinity gradient energy is identified as a promising and abundant source of sustainable energy, which is obtained from the ionic gradient between sea water and fresh water ${ }^{1,2}$. Since Pattle's pioneering research on salinity gradient energy in $1954^{3}$, several techniques have been

\footnotetext{
Correspondence: Xiang-Yu Kong (kongxiangyu@mail.ipc.ac.cn) or Liping Wen (wen@mail.ipc.ac.cn)

${ }^{1}$ CAS Key Laboratory of Bio-inspired Materials and Interfacial Science, Technical Institute of Physics and Chemistry, Chinese Academy of Sciences, Beijing, PR China

${ }^{2}$ Key Laboratory of Green and Precise Synthetic Chemistry and Applications, Ministry of Education, College of Chemistry and Materials Science, Huaibei Normal University, Huaibei, Anhui, PR China

Full list of author information is available at the end of the article

These authors contributed equally: Yue Sun, Yadong Wu
}

developed to maximize the conversion of salinity gradient energy into electricity. One of the most promising methods among these techniques is membrane-based reverse electrodialysis (RED), which utilizes an ion-selective membrane to directly generate electricity through ion migration without mechanical components ${ }^{4-6}$. The ions selectively transit through the membrane to induce a diffusive voltage between the membrane ${ }^{7}$, which is largely affected by the temperature distribution of the system ${ }^{8}$. In recent decades, synthetic polymeric membranes have become the core component in a wide variety of domains, including liquid and gas separation ${ }^{9}$, ultrafiltration ${ }^{10}$, and energy generation/storage ${ }^{11,12}$. Recently, nanofluidic membranes have been used in RED systems to achieve high power density ${ }^{13,14}$. In addition, solutions with

\section{(c) The Author(s) 2021}

(c) (i) Open Access This article is licensed under a Creative Commons Attribution 4.0 International License, which permits use, sharing, adaptation, distribution and reproduction cc in any medium or format, as long as you give appropriate credit to the original author(s) and the source, provide a link to the Creative Commons license, and indicate if changes were made. The images or other third party material in this article are included in the article's Creative Commons license, unless indicated otherwise in a credit line to the material. If material is not included in the article's Creative Commons license and your intended use is not permitted by statutory regulation or exceeds the permitted use, you will need to obtain permission directly from the copyright holder. To view a copy of this license, visit http://creativecommons.org/licenses/by/4.0/. 

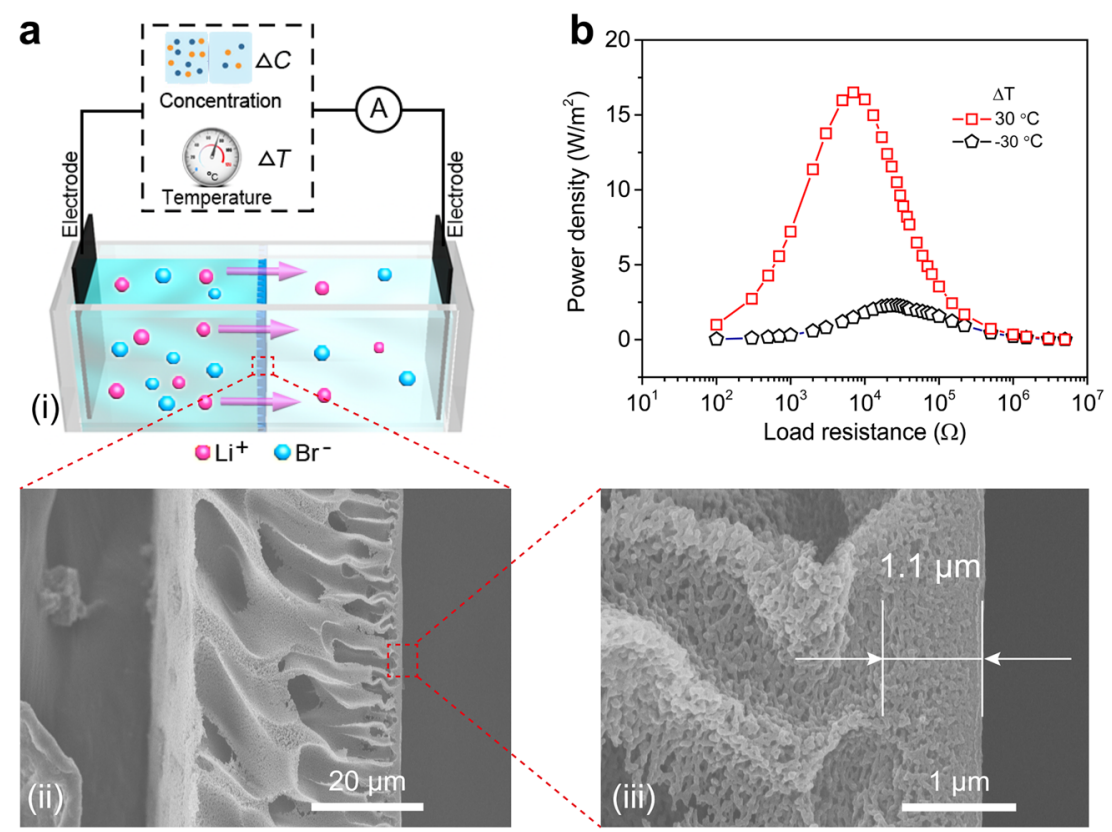

Fig. 1 Thermoenhanced osmotic power generator via an asymmetric SPEEK/PES blend membrane and LiBr solution. a Schematic of the energy conversion device (i), which combines an asymmetric SPEEK/PES blend membrane and a pair of LMO/CNT electrodes (ii). Cross-sectional SEM image of the SPEEK/PES blend membrane with a condensed $\sim 1.1 \mu \mathrm{m}$ surface layer (iii). $\mathbf{b}$ The device shows a very high power density of $\sim 16.50 \mathrm{~W} / \mathrm{m}^{2}$ under a temperature gradient of $30^{\circ} \mathrm{C}$, which is much higher than that under a temperature gradient of $-30^{\circ} \mathrm{C}$.

different salinities are also natural reservoirs, which can be used as an intermediate for generating electricity from other energy conversion methods. By employing a nanofluidic RED membrane, the energy resources can be connected together with proper system designs.

Osmotic energy conversion using RED technology is largely affected by several factors, including the (1) salt solubility in water, (2) equivalent conductivity of the aqueous solution, (3) activity coefficient ratio, and (4) external field factors (e.g., thermal energy) ${ }^{15-17}$. In this respect, $\mathrm{LiBr}$ fits the requests as an RED working solution due to its excellent solubility (i.e., $13.13 \mathrm{M}$ at $25^{\circ} \mathrm{C}$ ), which is much higher than that of $\mathrm{NaCl}$ (i.e., $5.50 \mathrm{M}$ at $25^{\circ} \mathrm{C}$ ). Thus, the use of $\mathrm{LiBr}$ leads to a higher concentration gradient in the RED system, which results in a higher output power density. Moreover, some factors, such as the thermal field, can significantly affect the osmotic conversion performance. A temperature gradient is present between the high- and low-concentration solutions during the membrane distillation (MD) process, which utilizes low-grade heat (e.g., solar energy, geothermal energy, or waste heat) in the regeneration process of closed-loop RED. This is because MD utilizes a thermal field to promote the transport of vapor in the hydrophobic membrane. Thus, it is a sustainable method to regenerate highand low-concentration $\mathrm{LiBr}$ solutions, which is similar to the regeneration of rivers from the evaporation of sea water. The temperatures of the two compartments are different, which means that the thermal-field effect exists across the membrane. However, the current research using RED technology to generate electricity from artificial $\mathrm{NaCl}$-water solutions or natural rivers and sea water is typically near room temperature, which largely reduces its application field.

Herein, the feasibility of electricity generation via a $\mathrm{LiBr}$ solution and heat gradient is validated experimentally in an RED system. An osmotic power generator for electricity generation is built, which converts the osmotic energy existing in $\mathrm{LiBr}$ solutions with different concentrations and temperatures (Fig. 1a, i). This RED system is composed of an asymmetric sulfonated poly(ether ether ketone)/poly(ether sulfone) (SPEEK/PES) blend membrane and a pair of $\mathrm{LiMn}_{2} \mathrm{O}_{4} /$ carbon nanotube (LMO/ $\mathrm{CNT}$ ) electrodes. The high thermal stability and low cost of the membrane are important for practical applications. The SPEEK/PES blend membrane shows a typical asymmetric finger-like structure with an average thickness of $\sim 37 \mu \mathrm{m}$ (Fig. 1a, ii). The ion selective layer of the membrane is the thin top layer whose thickness is $\sim 1.1 \mu \mathrm{m}$ (Fig. 1a, iii). The thin top layer contains hydrophilic groups (i.e., the sulfonated groups in SPEEK) that are beneficial for ion selective transport in the membrane. Additionally, as a proof of concept, we combine the RED with a heat gradient, and the system can reach a very high power density of $\sim 16.50 \mathrm{~W} / \mathrm{m}^{2}$ with a $30{ }^{\circ} \mathrm{C}$ temperature gradient at a 50 -fold concentration gradient (Fig. 1b). 
There is a heat gradient between the solutions in many practical applications, while reported RED systems rarely consider this issue. The current work offers a promising method for enhancing electricity conversion from the salinity gradient energy of $\mathrm{LiBr}$ solution with an applied heat gradient, indicating the prospect of the use of $\mathrm{LiBr}$ solution in RED.

\section{Experimental section \\ Materials and chemicals}

Poly(ether ether ketone) (PEEK, Sigma-Aldrich, Shanghai), polyether sulfone (PES, BASF, Shanghai) and N,N-dimethylacetamide (DMAc, Sigma-Aldrich, Shanghai) were utilized to fabricate membranes. Isopropanol (IPA, 99.7\%) acquired from J\&K Beijing was used for the posttreatment of the membranes. Lithium bromide (J\&K Beijing) was used to determine the RED performance of the membranes. $\mathrm{LiMn}_{2} \mathrm{O}_{4}$ (LMO, Sigma-Aldrich, Shanghai), carbon nanotube (CNT, Aladdin, Shanghai), N-methyl pyrrolidone (NMP, Aladdin, Shanghai) and poly(vinylidene fluoride) (PVDF, MTI, Shenzhen) were used to prepare the electrode composite material. Degassed Milli-Q water was produced by a Milli-Q ultrapure water system (Millipore, USA). All chemicals were used as received.

\section{Synthesis of SPEEK}

SPEEK was synthesized by sulfonating PEEK with concentrated sulfuric acid. Briefly, $5 \mathrm{~g}$ of PEEK and $75 \mathrm{~mL}$ of concentrated sulfuric acid (98wt\%) were added into a $250 \mathrm{~mL}$ three-necked flask and stirred for $3 \mathrm{~h}$ until the PEEK dissolved completely. Then, the homogeneous solution was heated with stirring at $60^{\circ} \mathrm{C}$ for another $2.5 \mathrm{~h}$. Finally, the solution was slowly dropped into a large amount of ice-cold Milli-Q water to precipitate the SPEEK. SPEEK was filtered and washed with Milli-Q water several times until the $\mathrm{pH}$ of the percolate was $\sim 7$.

\section{Fabrication of asymmetric SPEEK/PES blend membranes}

Asymmetric SPEEK/PES blend membranes were fabricated via nonsolvent-induced phase inversion assisted by a nonsolvent additive. First, a certain mass ratio of SPEEK and PES was mixed together and stirred in N,N-dimethylacetamide (DMAc) for $1.5 \mathrm{~h}$ at room temperature to form a homogeneous polymer solution. Then, $0.2 \mathrm{~mL}$ of Milli-Q water was added and stirred for $0.5 \mathrm{~h}$ at $70{ }^{\circ} \mathrm{C}$. After removing the air bubbles, the polymer solution was cast onto a clean glass plate at room temperature and below $50 \%$ relative humidity. Afterward, the glass plate was immersed in Milli-Q water immediately to create a membrane with an asymmetric structure. These asymmetric membranes were peeled off from the glass plate and soaked in Milli-Q water. Finally, the asymmetric membrane was immersed in IPA for $36 \mathrm{~h}$ and then lifted and evaporated at room temperature for $24 \mathrm{~h}$.

\section{Fabrication of LMO/CNT electrodes}

Typically, $50 \mathrm{mg}$ of CNTs was dispersed in $25 \mathrm{~mL}$ of NMP with ultrasonic processing for $1 \mathrm{~h}$. Then, $300 \mathrm{mg}$ of $\mathrm{LiMn}_{2} \mathrm{O}_{4}$ was added into the mixed solution with further ultrasonic treatment for $0.5 \mathrm{~h}$. The $\mathrm{LMO} / \mathrm{CNT}$ composite material was obtained by vacuum filtration. In a typical electrode preparation, the $\mathrm{LMO} / \mathrm{CNT}$ composite material and PVDF were mixed in a weight ratio of 9:1 in NMP to form a slurry, and then the slurry was uniformly pasted on $\mathrm{Al}$ foil. Finally, the electrodes were vacuum dried at $45^{\circ} \mathrm{C}$ to remove the solvent.

\section{Characterization}

\section{Electrical characterization}

Electrical measurements were obtained with a Keithley 6487 semiconductor picoammeter (Keithley Instruments, Cleveland, $\mathrm{OH})$. The asymmetric SPEEK/PES blend membranes were clamped between two compartments. For the ionic transport measurement, identical $\mathrm{KCl}$ solutions from $0.1 \mu \mathrm{M}$ to $1 \mathrm{M}$ were used to fill the two chambers containing a pair of $\mathrm{Ag} / \mathrm{AgCl}$ electrodes as voltage application terminals. The $\mathrm{CV}$ measurements were carried out with an electrochemical workstation (CHI-660E, Chenhua, Shanghai) utilizing a threeelectrode system. The membrane was placed between two compartments of the two-cell system. Briefly, $20 \mathrm{mM}$ anionic $\left[\mathrm{Fe}(\mathrm{CN})_{6}\right]^{3-}$ and cationic $\left[\mathrm{Ru}\left(\mathrm{NH}_{3}\right)_{6}\right]^{3+}$ probes (the supporting electrolyte was $0.1 \mathrm{M} \mathrm{KCl}(\mathrm{pH} \approx 4.3)$ ) were selected and added into one compartment, while the other compartment was added into Milli-Q water. After $1 \mathrm{~h}$, exudation was used in the CV measurements. Platinum wires served as the working electrode and counter electrode, while a $\mathrm{Ag} / \mathrm{AgCl}$ electrode was used as the reference electrode. The scan rate was set at $10 \mathrm{mV} / \mathrm{s}$, and the measurements were conducted at $\sim 22^{\circ} \mathrm{C}$. For the energy conversion tests, a pair of $\mathrm{LMO} / \mathrm{CNT}$ electrodes was utilized to apply a transmembrane potential. The feed and permeate chambers were filled with a highconcentration $\mathrm{LiBr}$ solution and a low-concentration $\mathrm{LiBr}$ solution, respectively. The testing area of the membrane was $0.20 \mathrm{~mm}^{2}$.

\section{Permeation experiments}

Permeation experiments were performed using a twocell system separated by an asymmetric SPEEK/PES blend membrane. The permeability rate was tested separately to avoid interference because the fluorescence emission of rhodamine $6 \mathrm{G}$ is much stronger than that of sulforhodamine. Either $0.1 \mathrm{mM}$ rhodamine $6 \mathrm{G}$ or $0.1 \mathrm{mM}$ sulforhodamine solution was added into the feed cell facing the bottom side of the membrane. The exudations 
in the receptor chamber were tested using a spectrofluorophotometer every $5 \mathrm{~min}$.

\section{Membrane structure characterization}

$1 \mathrm{H}$ NMR (nuclear magnetic resonance)measurements were obtained with a Bruker AVNANCE 400 spectrometer. Field-emission SEM (scanning electron microscope, Hitachi S-4800) at an accelerating voltage of $10 \mathrm{kV}$ was used to observe the membranes. Cross-sectional membrane samples were cryogenically fractured through the use of liquid nitrogen. The membrane samples were sputter-coated with gold before the SEM test. Contact angle measurements were obtained through the use of photographs, an OCA25 contact angle measuring instrument (Dataphysics, Germany) and ImageJ software. Each membrane was measured five times, and the average was calculated. XPS (X-ray photoelectron spectroscopy) spectra were obtained on a PHI Quantera scanning X-ray microprobe with a monochromated $\mathrm{Al} \mathrm{K} \alpha$ radiation source at $1486.7 \mathrm{eV}$. Surface zeta potentials were determined on a zeta potential analyzer (SurPASS 3, Anton Paar, Austria). The permeability tests of fluorophores were monitored by a spectrofluorophotometer (RF5301PC, SHIMADZU, Japan).

\section{Results and discussion}

Membrane characterization and ionic transport properties

Asymmetric SPEEK/PES blend membranes were fabricated by utilizing nonsolvent-induced phase inversion with the assistance of trace water as the nonsolvent additive (Supplementary Fig. S1). SPEEK was prepared by sulfonating PEEK with concentrated sulfuric acid, and the degree of sulfonation (DS) of SPEEK was 94.6\% according to the ${ }^{1} \mathrm{H}$ NMR technique (Supplementary Fig. S2). To obtain an asymmetric finger-like membrane, trace Milli-Q water was added to the SPEEK/PES casting solution as a nonsolvent additive. Usually, some additives increase the viscosity of a casting solution, inhibiting the mutual diffusion process of the solvent and nonsolvent owing to the reduced fluidity of a mixed solution ${ }^{18}$. The nonsolvent water induced gelation of the casting solution by forming a three-dimensional network due to hydrogen bonding interactions between the trace $\mathrm{H}_{2} \mathrm{O}$ and sulfonated groups in SPEEK, which slowed down the movement of the polymer chains and the coalescence of the polymer-poor phase $^{19,20}$. The polymer solution was cast onto a glass plate, and the solution thickness was controlled by the casting knife ${ }^{21}$. Then, the glass plate was immediately transferred into a Milli-Q water bath at $\sim 20^{\circ} \mathrm{C}$ to form a membrane. Afterward, the membrane reorganization process was conducted. The membrane was first immersed in IPA for $36 \mathrm{~h}$ and then dried at room temperature. The reorganization of polymer chains (hydrophilic) occurs during both the IPA immersion and evaporation processes, forming a more hydrophilic channel surface with more sulfonated groups in the asymmetric SPEEK/PES blend membrane.

The microstructure of the membrane top surface displays a dense structure (Supplementary Fig. S3a), while the bottom surface morphology of the membrane shows large pores (Supplementary Fig. S3b, c, d). The pores in the dense layer of the SPEEK/PES membrane have a diameter of $\sim 11 \mathrm{~nm}$. Membranes with different thicknesses were obtained by adjusting the height of the casting knife (Supplementary Fig. S4). The structure of the membranes prepared by the phase inversion method is mainly determined by the solvent/nonsolvent exchange rate, SPEEK/PES polymer interaction, and viscosity of the casting solution ${ }^{22,23}$. With increasing casting solution concentration, the macrovoid size decreases and the sponge-like region increases (Supplementary Figs. S5-S8). These changes occur because the higher viscosity of the casting solution slows down the coagulation process and reduces the solvent/nonsolvent exchange rate $^{24}$. The major mass loss occurred in the temperature range of $500-650{ }^{\circ} \mathrm{C}$, corresponding to polymer combustion (Supplementary Fig. S9). A high-temperature LiBr solution can be utilized due to the heat resistance of the membrane. In addition, the cost of the SPEEK/PES membrane, approximately $8.7 \mathrm{USD}(\$) / \mathrm{m}^{2}$ (Table S1), is much lower than the international cost target (11 USD $(\$) / \mathrm{m}^{2}$ ) for ion-selective membrane-based RED technology. Collectively, this asymmetric structure is related to the solvent/nonsolvent exchange and polymer solidification processes during the phase inversion process.

The ionic transport properties of the asymmetric SPEEK/PES blend membranes with and without IPA treatment were examined by obtaining current-voltage $(I-V)$ measurements. After IPA-induced membrane reorganization, the ionic current increases from approximately $0.10 \mu \mathrm{A}$ to $0.35 \mu \mathrm{A}$ (Fig. 2a). The zeta potential measurements confirm that the surface charge density of the membrane increases after reorganization, which means that the groups containing oxygen $\left(-\mathrm{O}-,-\mathrm{SO}_{3}{ }^{-}\right.$, > $\mathrm{C}=\mathrm{O}$ ), especially the polar sulfonated groups, migrate to the channel surface through the IPA treatment (Fig. 2a, inset). This migration can also be confirmed by the X-ray photoelectron spectroscopy (XPS) results, which show that the atomic content of sulfur and oxygen on the top layer of the membrane increases after IPA treatment (Tables S2,3). The transmembrane conductance deviates from bulk behavior at $0.01 \mathrm{M}$ and gradually approaches plateaus at lower concentrations, which means that ionic transport through the asymmetric SPEEK/PES blend membrane is governed by the surface charge (Fig. 2b). Additionally, the reorganized membrane with more charged groups in the channels demonstrate higher transmembrane conductance. 

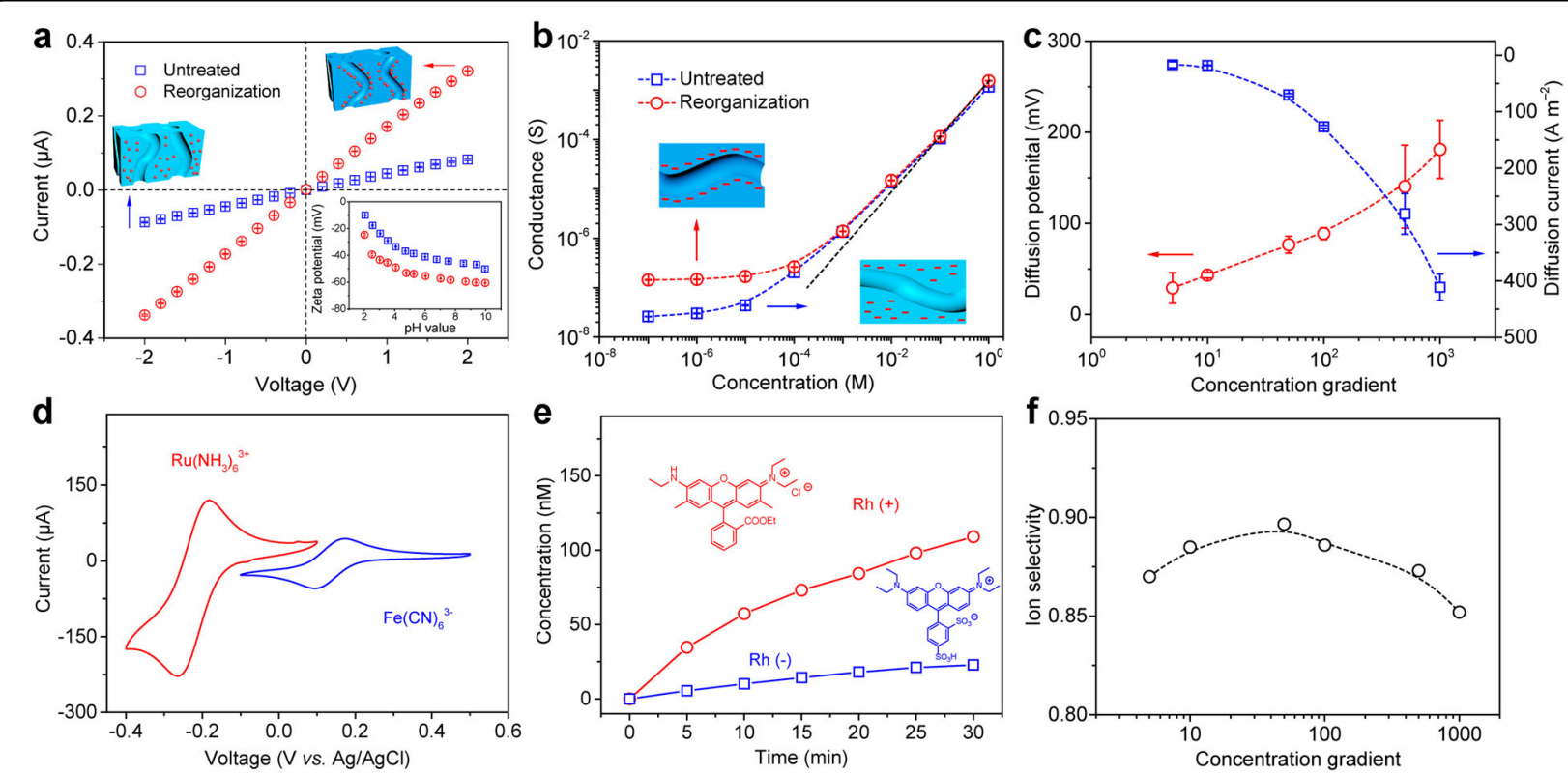

Fig. 2 lonic transport properties of the asymmetric SPEEK/PES blend membrane. a / - $V$ curves of the untreated and reorganized asymmetric SPEEK/PES blend membranes recorded in $10^{-5} \mathrm{M} \mathrm{KCl}$ solution. Inset is the surface zeta potential of these two SPEEK/PES blend membranes at different $\mathrm{pH}$ values. $\mathbf{b}$ Conductance measurement in $\mathrm{KCl}$ electrolyte. The ionic conductance of the asymmetric SPEEK/PES blend membrane changes as the electrolyte concentration decreases, and it clearly shows that at low concentrations, the ionic conductance of both membranes is governed by the surface charge. c Diffusion potential and diffusion current recorded with the series of concentration gradients of LiBr solution. Both the CV curves (d) and time-concentration curves in the permeation experiments (e) indicate the good cation selectivity of the reorganized asymmetric SPEEK/PES blend membrane $\left(\left[\mathrm{Ru}\left(\mathrm{NH}_{3}\right)_{6}\right]^{3+}\right.$ as a cationic electroactive probe (red trace); $\left[\mathrm{Fe}(\mathrm{CN})_{6}\right]^{3-}$ as an anionic electroactive probe (blue trace); rhodamine $6 \mathrm{G}$ $(\mathrm{Rh}(+)$, red circle trace); sulforhodamine (Rh $(-)$, blue square trace)). $\mathbf{f}$ Relationship between the ion selectivity of the membrane and concentration gradient. The low-concentration $\mathrm{LiBr}$ solution facing the top side of the membrane was fixed at $0.01 \mathrm{M}$.

To investigate the ion transport behavior of the membrane under a concentration gradient, $I_{\text {diff }}$ and $V_{\text {diff }}$ were measured. $V_{\text {diff }}$ originates from the ion selectivity of the membrane, which can result in the difference in the diffusive fluxes of anions and cations. The diffusion potential can be calculated by $V_{\text {diff }}=V_{\text {app }}-E_{\text {redox }}$ (Supplementary Note 1). Along with the increase in the concentration gradient, $I_{\text {diff }}$ and $V_{\text {diff }}$ both increase (Fig. 2c). $V_{\text {diff }}$ originates from the ion selectivity of the membrane, the main diffusive flux of cations (i.e., $\mathrm{Li}^{+}$). Due to the sulfonated groups in SPEEK, the membrane exhibits excellent cation selectivity. The cation selectivity was first investigated by electroactive redox probes (i.e., $\left[\mathrm{Ru}\left(\mathrm{NH}_{3}\right)_{6}\right]^{3+}$ and $[\mathrm{Fe}$ $\left.(\mathrm{CN})_{6}\right]^{3-}$ ) in cyclic voltammetry $(\mathrm{CV})$ (Fig. $2 \mathrm{~d}$ ). The diffusion coefficients of $\left[\mathrm{Ru}\left(\mathrm{NH}_{3}\right)_{6}\right]^{3+}$ and $\left[\mathrm{Fe}(\mathrm{CN})_{6}\right]^{3-}$ are $7.4 \times 10^{-6} \mathrm{~cm}^{2} / \mathrm{s}$ and $7.6 \times 10^{-6} \mathrm{~cm}^{2} / \mathrm{s}$, respectively ${ }^{25}$. The reduction/oxidation peaks of $\left[\mathrm{Ru}\left(\mathrm{NH}_{3}\right)_{6}\right]^{2+/ 3+}$ are observed at -0.27 and $-0.18 \mathrm{~V}$, respectively. Additionally, the reduction/oxidation peaks of $\left[\mathrm{Fe}(\mathrm{CN})_{6}\right]^{3-/ 4-}$ are observed at 0.094 and $0.17 \mathrm{~V}$, respectively. These curves show strong electrochemical peaks for the transport of the cationic probe $\left[\mathrm{Ru}\left(\mathrm{NH}_{3}\right)_{6}\right]^{3+}$ (red trace) and weak anionic peaks for the $\left[\mathrm{Fe}(\mathrm{CN})_{6}\right]^{3-}$ (blue trace) probe, and the peak currents of $\left[\mathrm{Ru}\left(\mathrm{NH}_{3}\right)_{6}\right]^{2+/ 3+}$ and $\left[\mathrm{Fe}(\mathrm{CN})_{6}\right]^{3-/ 4-}$ are approximately $228 \mu \mathrm{A}$ and $55 \mu \mathrm{A}$, respectively. Due to the negatively charged character of the membrane, the different diffusion abilities of the specific probe result in a distinct voltammetric response. To further confirm the ion selectivity of the asymmetric SPEEK/PES blend membrane, rhodamine (Rh) $6 \mathrm{G}$ and sulforhodamine with opposite charges (Fig. 2e) were chosen as fluorophores due to their high quantum yields for transmembrane transport measurements. Permeation experiments were conducted with a two-cell system, which was separated by an asymmetric membrane. The feed chamber was filled with fluorophore solutions $\left(1.0 \times 10^{-4} \mathrm{M}\right)$, and the permeability of both fluorophores was monitored by taking the fluorescence spectra of the solution in the receptor chamber every $5 \mathrm{~min}$. The permeability rate of $\mathrm{Rh}(+)$ is much larger than that of Rh (-), which corresponds to the $\mathrm{CV}$ test results. The ion selectivity was quantified by calculating the transference number of cations. With the increase in the concentration gradient, the transference number reaches a peak value at a 50 -fold salinity gradient of $\mathrm{LiBr}$ solution (Fig. 2f). The decrease in transference number under a higher salinity gradient could be due to the increase in concentration polarization ${ }^{26,27}$. 

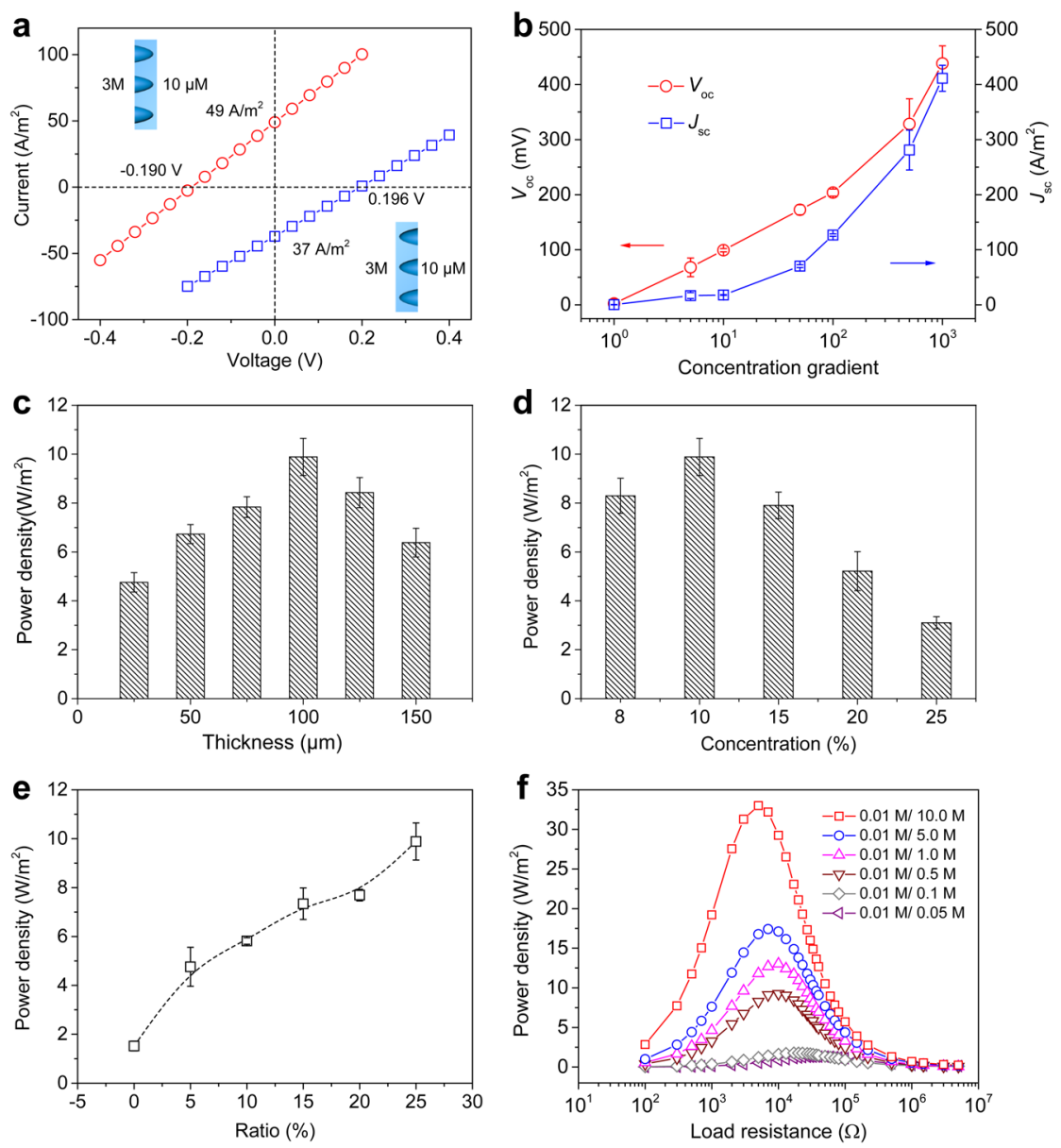

Fig. 3 High-performance osmotic energy conversion of asymmetric SPEEK/PES blend membranes. a /-V curves of the membrane with two opposite concentration gradient configurations. The $J_{\mathrm{SC}}$ and $V_{\mathrm{OC}}$ change from $49 \mathrm{~A} / \mathrm{m}^{2}$ and $190 \mathrm{mV}$ (concentrated $\mathrm{KCl}$ solution on the bottom side of the membrane, red circle) to $37 \mathrm{~A} / \mathrm{m}^{2}$ and $196 \mathrm{mV}$ (concentrated $\mathrm{KCl}$ solution on the top side of the membrane, blue square), respectively; thus, the corresponding inner resistance $\left(R_{\text {channel }}\right)$ increases by $\sim 36.6 \%$. $\mathbf{b} J_{\mathrm{SC}}$ and $V_{\mathrm{OC}}$ as functions of the concentration gradient. The low-concentration (LiBr) solution was placed on the top side of the membrane and fixed at $0.01 \mathrm{M}$. The output power density as a function of the (c) thickness of the casting solution, (d) polymer concentration in the casting solution, and (e) SPEEK/(SPEEK+PES) weight ratio. The high-salinity (LiBr) solution was placed on the bottom side of the membrane and fixed at $0.5 \mathrm{M}$, while the low-concentration (LiBr) solution was placed on the top side and fixed at $0.01 \mathrm{M}$. f Output power densities of the membrane under different concentration gradients from 5 to 1000 . The top side of the membrane faced the lowconcentration (LiBr) solution (0.01 M).

\section{Asymmetric SPEEK/PES blend membranes for osmotic power generation at room temperature}

The osmotic energy conversion performance of the asymmetric SPEEK/PES blend membrane was examined by applying a series of $\mathrm{LiBr}$ concentration gradient conditions. Additionally, the LiBr-water solution presents application prospects due to its higher theoretical power density and open-circuit voltage under the same salinity gradients ${ }^{15}$. Two opposite salinity gradient test directions were adopted to optimize the concentration gradient (Fig. 3a). When the diluted $\mathrm{KCl}$ solution (i.e., $10 \mu \mathrm{M}$ ) faces the top thin layer, the absolute values of the short-circuit current density $\left(J_{\mathrm{SC}}\right)$ and the open-circuit voltage $\left(V_{\mathrm{OC}}\right)$ are approximately $49 \mathrm{~A} / \mathrm{m}^{2}$ and $190 \mathrm{mV}$, respectively.
In the reversed concentration gradient configuration, the absolute value $J_{\mathrm{SC}}$ decreases to $\sim 37 \mathrm{~A} / \mathrm{m}^{2}$, and the $V_{\mathrm{OC}}$ increases to $\sim 196 \mathrm{mV}$. The calculated inner resistance ( $\left.R_{\text {channel }}\right)$ increases by $\sim 36.6 \%$, impeding the energy conversion. Ion transport is dominated by the thin top layer of the asymmetric membrane, which contains a large number of nanoscale channels. The thickness of the electrical double layer (EDL) in the nanoscale channels is determined by the ionic concentration, which largely affects the energy conversion ${ }^{7}$. Therefore, the former configuration was chosen in our following tests. For the energy conversion experiments, a pair of LMO/CNT electrodes was used to offer a transmembrane potential. This is because the commonly used $\mathrm{Ag} / \mathrm{AgCl}$ electrode 
reacts with $\mathrm{Br}^{-}$to form $\mathrm{AgBr}$ that decomposes easily when irradiated with light. Normally, LMO is employed as a cathode in aqueous $\mathrm{Li}$-ion batteries because $\mathrm{Li}^{+}$-ion (de)intercalation occurs near the upper limit of the stability window of the aqueous electrolyte ${ }^{28}$. The electrode reactions in the high-concentration solution are $\mathrm{LiMn}^{3+} \mathrm{Mn}^{4+} \mathrm{O}_{4}=\mathrm{Li}_{1-\mathrm{x}} \mathrm{Mn}^{3+}{ }_{1-\mathrm{x}} \mathrm{Mn}^{4+}{ }_{1+\mathrm{x}} \mathrm{O}_{4}+\mathrm{xLi}^{+}+\mathrm{xe}^{-}$ $(0<x<1)$. The electrode reactions in the lowconcentration solution are $\mathrm{LiMn}^{3+} \mathrm{Mn}^{4+} \mathrm{O}_{4}+\mathrm{xLi}^{+}+$ $\mathrm{xe}^{-}=\mathrm{Li}_{1+\mathrm{x}} \mathrm{Mn}^{3+}{ }_{1+\mathrm{x}} \mathrm{Mn}^{4+}{ }_{1-\mathrm{x}} \mathrm{O}_{4} \quad(0<\mathrm{x}<1)^{29}$. The SEM images of the LMO/CNT electrodes (Supplementary Fig. S10a) show that the LMO particles are uniformly distributed in the LMO/CNT composite. The contact angle of the electrode is $\sim 49.5^{\circ}$, showing the hydrophilicity of the electrode (Supplementary Fig. S10b). Additionally, it was proven that the electrodes can be regenerated (Supplementary Note 2, Fig. S11-S13). First, the $J_{\mathrm{SC}}$ and $V_{\mathrm{OC}}$ of the SPEEK/PES membrane at a series of concentration gradient conditions are presented in Fig. 3b. The $\mathrm{LiBr}$ concentration in the low-concentration cell $\left(c_{\mathrm{LiBr}}\right.$, low $)$ was fixed at $0.01 \mathrm{M}$, while the concentration in the high-concentration cell $\left(\mathrm{c}_{\mathrm{LiBr}}\right.$, high $)$ increased from 0.01 to $10 \mathrm{M}$. Both the $J_{\mathrm{SC}}$ and $V_{\mathrm{OC}}$ values gradually increase with increasing $\mathrm{C}_{\mathrm{LiBr}}$, high and the maximum values reach approximately $411 \mathrm{~A} / \mathrm{m}^{2}$ and $438 \mathrm{mV}$, respectively. The theoretical open-circuit voltage was calculated (Supplementary Note 3), and the theoretical values are slightly larger than the experimental value. The deviations from the theoretical values are approximately $13 \%, 11 \%, 10 \%, 12 \%, 13 \%$, and $15 \%$ under 5 -fold, 10 -fold, 50-fold, 100-fold, 500-fold, and 1000-fold salinity gradients, respectively (Supplementary Fig. S14).

Thereafter, screening of the casting solution thickness was conducted, as well as the polymer concentration in the casting solution and SPEEK/(SPEEK + PES) weight ratio. The output power density can be calculated by $P_{\max }=I^{2} \times R_{\mathrm{L}}$, and a maximum value can be obtained when the load resistance is equal to the total resistance of the membrane, electrodes, and salt solutions. The maximum power density first increases from $\sim 4.76 \mathrm{~W} /$ $\mathrm{m}^{2}$ to the peak value of $\sim 9.26 \mathrm{~W} / \mathrm{m}^{2}$ and then decreases to $\sim 6.38 \mathrm{~W} / \mathrm{m}^{2}$ when the thickness of the casting solution increases from $25 \mu \mathrm{m}$ to $100 \mu \mathrm{m}$ and then to $150 \mu \mathrm{m}$, respectively (Fig. 3c); these thicknesses correspond to the increasing thickness of the top layer from approximately 0.63 to $1.10 \mu \mathrm{m}$ and further to $\sim 1.29 \mu \mathrm{m}$ (Supplementary Fig. S4). The increase in the top layer thickness can simultaneously increase the ion selectivity and membrane resistance, and the power density reaches a peak value with an $\sim 1.10 \mu \mathrm{m}$ top layer to balance the two opposite effects. Similarly, the optimum polymer concentration of casting solution is screened to be $10 \%$ (Fig. 3d), corresponding to the maximum power density (i.e., $~ 9.26 \mathrm{~W} / \mathrm{m}^{2}$ ). For the low concentration of casting solution (i.e., $8 \%$ ), the membrane showing large pores in the top layer (Supplementary Fig. S5) induces relatively poor ion selectivity along with low output current density (Supplementary Fig. S15a) and power density. Additionally, the continual increase in casting solution concentration generally increases the compactness of membranes, which reduces the $\mathrm{Li}^{+}$-ion flux through the membrane. In addition, with increasing power density from $\sim 1.52 \mathrm{~W} / \mathrm{m}^{2}$ to $\sim 9.26 \mathrm{~W} / \mathrm{m}^{2}$, the SPEEK/(SPEEK + PES) weight ratio in the mixed solution gradually increases from 0 to $25 \mathrm{wt} \%$ (Fig. 3e); moreover, the current density increases (Supplementary Fig. S15b) due to the increasing number of sulfated groups in the membrane. As the sulfur atomic content in SPEEK is lower than that in PES, the corresponding sulfur atomic content decreases almost linearly as the SPEEK/(SPEEK + PES) weight ratio increases (Supplementary Fig. S16a, b). For a membrane used in aqueous solution, the wettability of the membrane is a very important factor in determining the permeate flux behavior ${ }^{24}$. The hydrophilic sulfated groups in SPEEK largely affect the wettability of the SPEEK/PES membrane. Thus, with the increase in the SPEEK/(SPEEK + PES) weight ratio in the casting solution, the contact angle of the membrane decreases from approximately $94.3^{\circ}$ to $34.8^{\circ}$ (Supplementary Fig. S16c), showing a more hydrophilic membrane $^{22}$. The contact angle decreases in two different trends before and after 10\% SPEEK/(SPEEK + PES), which might stem from the hydrophilic part of SPEEK interacting with IPA during the reorganization process ${ }^{30}$. Thus, when the SPEEK/(SPEEK + PES) weight ratio is $<10 \%$, IPA can effectively interact with the "few" sulfated groups in the membrane; when the SPEEK/(SPEEK + PES) weight ratio is $>10 \%$, the ability of IPA to bring sulfated groups to the channel surface is relatively insufficient due to the "excessive" content of sulfated groups and a flat contact angle decrease. This mechanism is also supported by the sulfur atomic variation tendency (Supplementary Fig. S16b) ${ }^{31}$.

As the concentration of $\mathrm{LiBr}$ can reach $\sim 13 \mathrm{M}$ due to its very high solubility, the current system can work under extended concentration gradient conditions. The $\mathrm{C}_{(\mathrm{LiBr} \text {, low })}$ was set at $0.01 \mathrm{M}$. As shown in Fig. 3f, the peak power density values are approximately $1.32 \mathrm{~W} / \mathrm{m}^{2}$, $1.78 \mathrm{~W} / \mathrm{m}^{2}, 9.26 \mathrm{~W} / \mathrm{m}^{2}, 13.03 \mathrm{~W} / \mathrm{m}^{2}, 17.41 \mathrm{~W} / \mathrm{m}^{2}$, and $33.00 \mathrm{~W} / \mathrm{m}^{2}$ for the 5-fold, 10-fold, 50-fold, 100-fold, 500 -fold, and 1000-fold salinity gradients, respectively. The current densities increase gradually with increasing concentration gradient (Supplementary Fig. S17). Furthermore, for the above salinity gradients, the corresponding efficiencies are approximately $27.4 \%, 29.6 \%$, $31.5 \%, 29.8 \%, 27.8 \%$, and 24.8\% (Supplementary Note 4, Table S4). The high solubility of $\mathrm{LiBr}$ in water is surely beneficial for osmotic energy harvesting. 

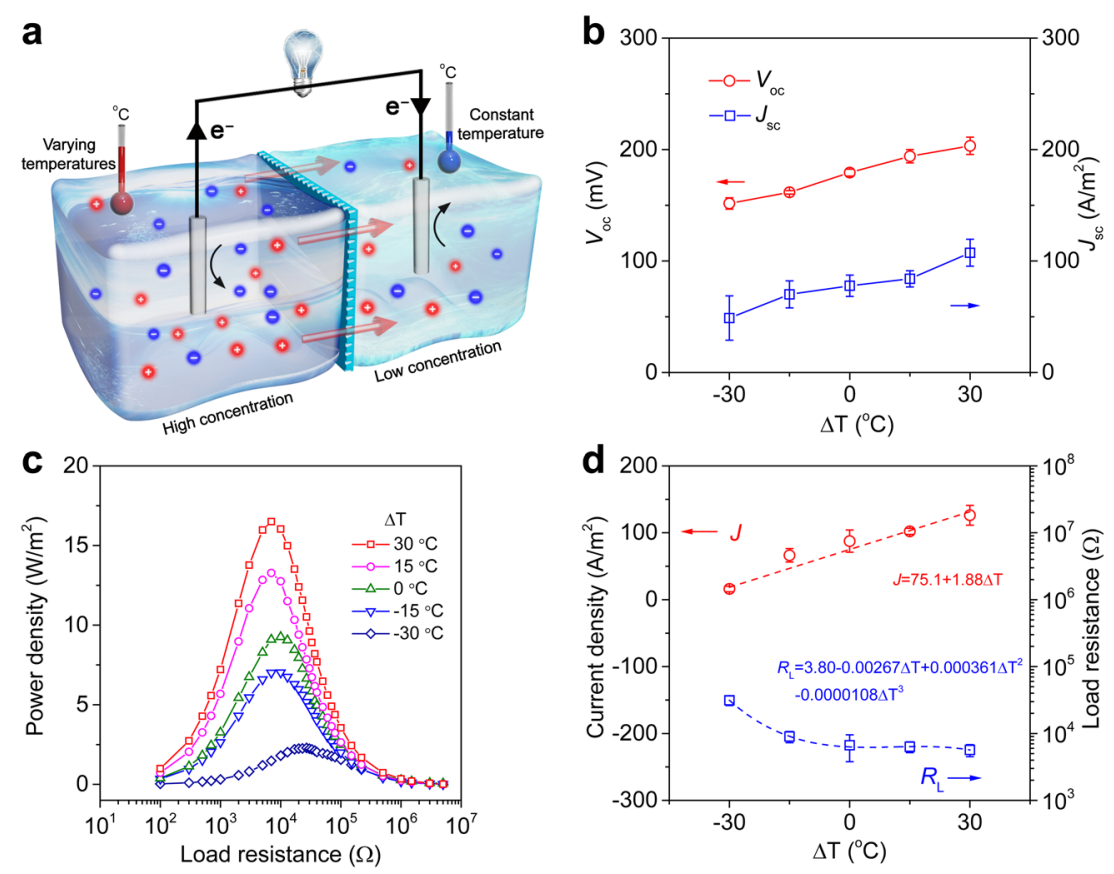

Fig. 4 Osmotic energy conversion performance under heat gradients. a Schematic illustration of the energy harvesting process by using the asymmetric SPEEK/PES blend membrane with a series of temperature gradients. The $\Delta T$ was calculated by $\Delta T=T_{h c}-T_{\text {lcc }}$. The temperature on the low-concentration $\left(T_{1 C}\right)$ side remained at $25^{\circ} \mathrm{C}$; the temperatures on the high-concentration $\left(T_{h c}\right.$ ) side gradually changed from $-5^{\circ} \mathrm{C}$ to $10,25,40$, and $55^{\circ} \mathrm{C}$. Thus, the resulting $\Delta T$ values were $-30,-15,0,15$, and $30^{\circ} \mathrm{C}$. b Changes in the measured $J_{S C}$ and $V_{\mathrm{OC}}$ with increasing $\Delta T$. c Output power densities of the asymmetric SPEEK/PES blend membrane with a 50-fold concentration difference with a series of $\Delta T$ from -30 to $30^{\circ} \mathrm{C}$. $\mathbf{d}$ Current density and load resistance at the peak power density change along with $\Delta \mathrm{T}$.

\section{Thermal-field effect on energy conversion}

The thermal-field effect on energy conversion under a certain concentration gradient was evaluated. Figure 4a is a schematic illustration of the energy conversion process under a series of temperature gradients. The high and low concentrations of $\mathrm{LiBr}$ solutions were set at $0.5 \mathrm{M}$ and $0.01 \mathrm{M}$, respectively; the temperature of the low salinity chamber $\left(\mathrm{T}_{\mathrm{lc}}\right)$ was set at $25^{\circ} \mathrm{C}$, and the temperature of the high salinity chamber $\left(\mathrm{T}_{\mathrm{hc}}\right)$ was gradually increased from $-5^{\circ} \mathrm{C}$ to $10^{\circ} \mathrm{C}, 25^{\circ} \mathrm{C}, 40^{\circ} \mathrm{C}$, and $55^{\circ} \mathrm{C}$. The $\Delta \mathrm{T}$ of the two chambers is defined as $\Delta \mathrm{T}=\mathrm{T}_{\mathrm{hc}}-\mathrm{T}_{\mathrm{lc}}$. The corresponding $J_{\mathrm{SC}}$ and $V_{\mathrm{OC}}$ values under different temperature gradients are shown in Fig. $4 \mathrm{~b}$. Both the $J_{\mathrm{SC}}$ and $V_{\mathrm{OC}}$ values increase gradually as $\Delta \mathrm{T}$ increases and reach maximum values of approximately $107 \mathrm{~A} / \mathrm{m}^{2}$ and $203 \mathrm{mV}$, respectively. Under the 50-fold salinity gradient, the corresponding power densities increase from approximately $2.29 \mathrm{~W} / \mathrm{m}^{2}$ to $16.50 \mathrm{~W} / \mathrm{m}^{2}$ when $\Delta \mathrm{T}$ increases from -30 to $30^{\circ} \mathrm{C}$ (Fig. $4 \mathrm{c}$ and Supplementary Figs. S18, 19). When both cells are set at $55^{\circ} \mathrm{C}$, the output power density reaches $\sim 18.8 \mathrm{~W} / \mathrm{m}^{2}$ (Supplementary Fig. S20). According to the previous theoretical calculation, the LiBr-water solution offers a higher power density than the $\mathrm{NaCl}$-water solution ${ }^{15}$, and the comparison among existing technologies and this work are shown in Table S5. The osmotic energy conversion using $\mathrm{LiBr}$ solution generates a higher output power density than that of $\mathrm{NaCl}$ solution. The counterion flux density is almost zero under open-circuit conditions, and the concentration gradient inside the membrane is also almost negligible. Therefore, the physical explanation of the generation of a potential drop in the membrane caused by the thermal-field effect can be explained by the equation below ${ }^{32}$ :

$$
Q_{i}^{m} d \ln T+z_{i} F d \phi^{m}=0
$$

where $Q_{i}^{m}$ is the heat of transport of ionic species $i(i=1$, 2), $T$ is the thermodynamic temperature, $z_{i}$ is the charge number of ionic species $i, F$ is the Faraday constant, and $\phi^{m}$ is the electrostatic potential inside the membrane.

If $Q_{i}^{m}>0$, the ions tend to move toward chambers of lower temperature. Thus, an electric field is generated inside the membrane, and current occurs under closedcircuit conditions. Moreover, the corresponding conversion efficiencies increase from approximately $15.2 \%$ to $46.8 \%$ (Table S6), indicating that the elevated temperature in the high salinity cell can largely promote energy conversion. Additionally, the current density and corresponding peak power density increase as $\Delta \mathrm{T}$ increases (Fig. 4d and Supplementary Fig. S21). The increase in 
current density along with the temperature elevation can be described by the equation $J=75.1+1.88 \Delta \mathrm{T}$. Interestingly, the resistance changes with temperature, which can be described as $R_{\mathrm{L}}=3.80-0.00267 \Delta \mathrm{T}$ $+0.000361 \Delta \mathrm{T}^{2}-0.0000108 \Delta \mathrm{T}^{3}$, and shows similar behavior with the reported resistance changing of a lithiumion battery ${ }^{33}$. The resistance decreases rapidly when $\mathrm{T}$ increases from -5 to $10^{\circ} \mathrm{C}$, while it decreases slowly when $\mathrm{T}$ increases from 10 to $55^{\circ} \mathrm{C}$. The slow decrease in resistance might be because the low salinity solution resistance is the main part of the total resistance. A higher peak power density value is obtained when the temperature in the high salinity chamber increases, which may be due to the increasing transmembrane migration of $\mathrm{Li}^{+}$-ion flux driven by the temperature gradient ${ }^{34-36}$. The traditional processes for converting low-grade energy to power are normally based on the production of mechanical energy. The energy is converted to electricity through a turbine, such as steam Rankine cycles and organic Rankine cycles. Several other technologies, including closed-loop RED technology, can also realize thermal-electric conversion, and we list all these technologies in Table S7 for comparison. Traditional techniques have demonstrated that the conversion of heat at low temperatures $\left(<100^{\circ} \mathrm{C}\right)$ to electricity have low efficiencies, high costs, and short lifetimes. The closed-loop reverse electrodialysis (RED) system generates electricity from low-grade heat at low temperature $\left(<100^{\circ} \mathrm{C}\right)^{37}$. In this regard, closed-loop RED is proposed as a suitable alternative to convert low-grade heat $\left(<100^{\circ} \mathrm{C}\right)$ to electricity.

\section{Conclusions}

In this study, we demonstrate the feasibility of designing a high-performance osmotic power generator using $\mathrm{LiBr}$ solutions. The osmotic power generator is composed of an asymmetric SPEEK/PES blend membrane and a pair of LMO/CNT electrodes. An asymmetric membrane with a finger-like structure is prepared via nonsolvent-induced phase inversion assisted by trace nonsolvent additives and followed by IPA reorganization treatment. More negatively charged groups are brought to the channel surface during the reorganization process, inducing excellent cation selectivity. The robust membrane can be used to harvest the Gibbs free energy of LiBr solutions with different concentrations and temperatures. The generator presents high-performance osmotic energy conversion using $\mathrm{LiBr}$ solutions with a power density of $\sim 9.26 \mathrm{~W} / \mathrm{m}^{2}$ under a 50-fold concentration gradient, and it can even achieve $\sim 33.00 \mathrm{~W} / \mathrm{m}^{2}$ under a 1000 -fold concentration gradient. In addition, the energy conversion of the system can be further promoted by thermal field regulation and reach a power density up to $\sim 16.50 \mathrm{~W} / \mathrm{m}^{2}$ under a temperature gradient $\left(\Delta T=30^{\circ} \mathrm{C}\right)$ at a 50 -fold concentration gradient. The current work shows the great potential of applying a LiBr solution-based RED system for highperformance osmotic energy conversion and further demonstrates the great potential of RED-based hybrid systems for harvesting other energy sources. In this regard, with a properly designed RED system, different energy sources, such as low-grade heat, light, sound, wind energy, and pressure, could be effectively extracted and converted into electricity, providing new viewpoints for combined energy harvesting.

\section{Acknowledgements \\ This work was supported by the National Natural Science Foundation of China (21625303, 21905287, 21988102), the National Key R\&D Program of China (2017YFA0206904, 2017YFA0206900, 2020YFA0710401), and the Key Research Program of the Chinese Academy of Sciences (QYZDY-SSW-SLH014). \\ Author details \\ ${ }^{1}$ CAS Key Laboratory of Bio-inspired Materials and Interfacial Science, Technical Institute of Physics and Chemistry, Chinese Academy of Sciences, Beijing, PR China. ${ }^{2}$ Key Laboratory of Green and Precise Synthetic Chemistry and Applications, Ministry of Education, College of Chemistry and Materials Science, Huaibei Normal University, Huaibei, Anhui, PR China. ${ }^{3}$ University of Chinese Academy of Sciences, Beijing, PR China. ${ }^{4}$ Key Laboratory of Cryogenics, Technical Institute of Physics and Chemistry, Chinese Academy of Sciences, Beijing, PR China}

\section{Competing interests}

The authors declare no competing interests.

\section{Publisher's note}

Springer Nature remains neutral with regard to jurisdictional claims in published maps and institutional affiliations.

Supplementary information The online version contains supplementary material available at https://doi.org/10.1038/s41427-021-00317-9.

Received: 4 February 2021 Accepted: 1 June 2021.

Published online: 2 July 2021

\section{References}

1. Logan, B. E. \& Elimelech, M. Membrane-based processes for sustainable power generation using water. Nature 488, 313-319 (2012).

2. Yip, N. Y. \& Elimelech, M. Thermodynamic and energy efficiency analysis of power generation from natural salinity gradients by pressure retarded osmosis. Environ. Sci. Technol. 46, 5230-5239 (2012).

3. Pattle, R. E. Production of electric power by mixing fresh and salt water in the hydroelectric pile. Nature 174, 660 (1954).

4. Mei, Y. \& Tang, C. Y. Y. Recent developments and future perspectives of reverse electrodialysis technology: a review. Desalination 425, 156-174 (2018).

5. Xin, W. et al. Biomimetic nacre-like silk-crosslinked membranes for osmotic energy harvesting. ACS Nano 14, 9701-9710 (2020).

6. Chen, J. et al. Ultrathin and robust silk fibroin membrane for high-performance osmotic energy conversion. ACS Energy Lett. 5, 742-748 (2020).

7. Huang, $X$. et al. Engineered PES/SPES nanochannel membrane for salinity gradient power generation. Nano Energy 59, 354-362 (2019).

8. Rui, L., Zhengfei, K., Zhichun, L. \& Wei, L. Temperature regulated reverse electrodialysis in charged nanopores. J. Membr. Sci. 561, 1-9 (2018).

9. Hou, L. et al. Separation of organic liquid mixture by flexible nanofibrous membranes with precisely tunable wettability. NPG Asia Mater. 8, e334 (2016).

10. An, X., Hu, Y., Wang, N., Wang, T. \& Liu, Z. Breaking the permeability-selectivity trade-off in thin-film composite polyamide membranes with a PEG-b-PSF-bPEG block copolymer ultrafiltration membrane support through postannealing treatment. NPG Asia Mater. 11, 13 (2019). 
11. Kim, D. W., Lee, J. H., Kim, J. K. \& Jeong, U. Material aspects of triboelectric energy generation and sensors. NPG Asia Mater. 12, 6 (2020).

12. Park, S., Lee, H., Kim, Y.-J. \& Lee, P. S. Fully laser-patterned stretchable microsupercapacitors integrated with soft electronic circuit components. NPG Asia Mater. 10, 959-969 (2018).

13. Zhang, Z. et al. Ultrathin and ion-selective janus membranes for highperformance osmotic energy conversion. J. Am. Chem. Soc. 139, 8905-8914 (2017).

14. Zhang, Z. et al. Improved osmotic energy conversion in heterogeneous membrane boosted by three-dimensional hydrogel interface. Nat. Commun. 11, 875 (2020).

15. Tamburini, A. et al. Reverse electrodialysis heat engine for sustainable power production. Appl. Energy 206, 1334-1353 (2017).

16. Veerman, J., Saakes, M., Metz, S. J. \& Harmsen, G. J. Reverse electrodialysis: performance of a stack with 50 cells on the mixing of sea and river water. J. Membr. Sci. 327, 136-144 (2009).

17. Long, R., Kuang, Z., Liu, Z. \& Liu, W. Temperature regulated reverse electrodialysis in charged nanopores. J. Membr. Sci. 561, 1-9 (2018).

18. Wang, Z.-G., Xu, Z.-K. \& Wan, L.-S. Modulation the morphologies and performance of polyacrylonitrile-based asymmetric membranes containing reactive groups: effect of non-solvents in the dope solution. J. Membr. Sci. 278 447-456 (2006).

19. Zhang, L. et al. Preparation of PES/SPSf blend ultrafiltration membranes with high performance via $\mathrm{H}_{2} \mathrm{O}$-induced gelation phase separation. J. Membr. Sci. 540, 136-145 (2017).

20. Zhao, Y. et al. Robust sulfonated poly (ether ether ketone) nanochannels for high-performance osmotic energy conversion. Natl. Sci. Rev. 7, 1349-1359 (2020).

21. Sun, Y. et al. Tailoring a poly(ether sulfone) bipolar membrane: osmotic-energy generator with high power density. Angew. Chem. Int. Ed. 59, 17423-17428 (2020).

22. Rahimpour, A. \& Madaeni, S. S. Polyethersulfone (PES)/cellulose acetate phthalate (CAP) blend ultrafiltration membranes: preparation, morphology, performance and antifouling properties. J. Membr. Sci. 305, 299-312 (2007).

23. Liu, Y., Koops, G. H. \& Strathmann, H. Characterization of morphology controlled polyethersulfone hollow fiber membranes by the addition of polyethylene glycol to the dope and bore liquid solution. J. Membr. Sci. 223 187-199 (2003).
24. Wang, W. Y. et al. Preparation and characterization of SLS-CNT/PES ultrafiltration membrane with antifouling and antibacterial properties. J. Membr. Sci. 548, 459-469 (2018).

25. Kim, J. \& Bard, A. J. Electrodeposition of single nanometer-size Pt nanoparticles at a tunneling ultramicroelectrode and determination of fast heterogeneous kinetics for $\mathrm{Ru}\left(\mathrm{NH}_{3}\right)_{6}{ }^{3+}$ reduction. J. Am. Chem. Soc. 138, 975-979 (2016).

26. Kim, S. J., Ko, S. H., Kang, K. H. \& Han, J. Direct seawater desalination by ion concentration polarization. Nat. Nanotechnol. 5, 297-301 (2010).

27. Dlugolecki, P., Gambier, A., Nijmeijer, K. \& Wessling, M. Practical potential of reverse electrodialysis as process for sustainable energy generation. Environ. Sci. Technol. 43, 6888-6894 (2009).

28. Okubo, M. et al. Fast Li-ion insertion into nanosized $\mathrm{LiMn}_{2} \mathrm{O}_{4}$ without domain boundaries. ACS Nano 4, 741-752 (2010).

29. Zampardi, G., Batchelor-McAuley, C., Katelhon, E. \& Compton, R. G. Lithium-iontransfer kinetics of single $\mathrm{LiMn}_{2} \mathrm{O}_{4}$ particles. Angew. Chem. Int. Ed. 56, 641-644 (2017).

30. Lu, W. et al. Solvent-induced rearrangement of ion-transport channels: a way to create advanced porous membranes for vanadium flow batteries. Adv. Funct. Mater. 27, 1604587 (2017).

31. Wang, T., Wang, Y.-Q., Su, Y.-L. \& Jiang, Z.-Y. Antifouling ultrafiltration membrane composed of polyethersulfone and sulfobetaine copolymer. J. Membr. Sci. 280, 343-350 (2006).

32. Jokinen, M., Manzanares, J. A., Kontturi, K. \& Murtomäki, L. Thermal potential of ion-exchange membranes and its application to thermoelectric power generation. J. Membr. Sci. 499, 234-244 (2016).

33. Ahmed, S. H., Kang, X. S. \& Shrestha, S. O. B. Effects of temperature on internal resistances of lithium-ion batteries. J. Energy Resour. Technol. 137, 031901 (2015).

34. Benneker, A. M., Klomp, J., Lammertink, R. G. H. \& Wood, J. A. Influence of temperature gradients on mono- and divalent ion transport in electrodialysis at limiting currents. Desalination 443, 62-69 (2018).

35. Suo, L. et al. Advanced high-voltage aqueous lithium-ion battery enabled by "water-in-bisalt" electrolyte. Angew. Chem. Int. Ed. 55, 7136-7141 (2016).

36. Zhang, C. et al. Anion-sorbent composite separators for high-rate lithium-ion batteries. Adv. Mater. 31, 1808338 (2019).

37. Ortega-Delgado, B. et al. Boosting the performance of a Reverse Electrodialysis-Multi-Effect Distillation Heat Engine by novel solutions and operating conditions. Appl. Energy 253, 113489 (2019). 